Check for updates

Cite this: RSC Adv., 2018, 8, 33314

Received 15th August 2018

Accepted 18th September 2018

DOI: $10.1039 / \mathrm{c} 8 \mathrm{ra06784h}$

rsc.li/rsc-advances

\section{Nanowires of polyaniline festooned silver coated paper electrodes for efficient solid-state symmetrical supercapacitors $\uparrow$}

\author{
A. Aashish, ${ }^{\text {ac }}$ C. Molji, ${ }^{\text {ac }}$ Ganesan Krishna Priya, ${ }^{d}$ Muthusamy Sankaran, ${ }^{d}$ \\ Unnikrishnan Nair Saraswathy Hareesh (D) ${ }^{* b c}$ and Sudha J. Devaki (D) *ac
}

\begin{abstract}
This paper demonstrates a facile strategy for the development of nanosilver decorated polyaniline coated (PAg) paper-based electrodes for the fabrication of solid-state symmetrical supercapacitors. PAg based printing paper was developed through a two-step process involving initial silver nucleation and growth on the paper followed by aniline polymerization. The developed electrically conductive paper exhibited a highly porous structure and excellent mechanical stability. Further symmetrical supercapacitors having the configuration PAg/electrolyte/PAg were fabricated and evaluated for electrochemical performance such as specific capacitance $\left(483 \mathrm{~F} \mathrm{~g}^{-1}\right.$ and $613 \mathrm{~F} \mathrm{~g}^{-1}$ in aqueous $1 \mathrm{M} \mathrm{H}_{2} \mathrm{SO}_{4}$ and PVA- $\mathrm{H}_{2} \mathrm{SO}_{4}$ gel electrolytes respectively), energy density (69.56 and $85.13 \mathrm{~W} \mathrm{~h} \mathrm{~kg}^{-1}$ ), and power density (243.44 and $405.375 \mathrm{~W} \mathrm{~kg}^{-1}$ ) and cycling stability (90\% of its capacitance retention even after 2000 cycles), exhibiting excellent performance under various bending conditions. All these exciting results suggest that the developed paper-based flexible solid-state energy device can serve as an efficient, sustainable, and lowcost energy storage system for portable microelectronic devices which are expected to revolutionize the perception of energy-storage devices in the electronics industry.
\end{abstract}

\section{Introduction}

The design and development of inexpensive, thin, flexible, light weight and even roll up portable electronic devices with multifunctional applications have recently received overwhelming interest among researchers from academia and industry. This warrants innovative technology for developing energy storage devices with less mass and flexibility endowed with high energy and power density even under bending conditions. Batteries and supercapacitors are the two important electrical energy storage systems where supercapacitors are superior to batteries in terms of life cycle, power density, environmental benignancy and safety. ${ }^{1-6}$

Various technologies such as microfabrication technology open up low-cost production for a high performing, robust, and

${ }^{a}$ Chemical Sciences and Technology Division, CSIR-National Institute for Interdisciplinary Science and Technology, Trivandrum-695019, India. E-mail: sudhajd2001@yahoo.co.in

${ }^{b}$ Materials Science and Technology Division, CSIR-National Institute for Interdisciplinary Science and Technology, Trivandrum-695019, India

${ }^{c}$ Academy of Scientific and Innovative Research (CSIR-NIIST Campus), CSIR-National Institute for Interdisciplinary Science and Technology, Trivandrum-695019, India ${ }^{d}$ ISRO Satellite Centre, Old Airport Road, Vimanapura Post, Bengaluru-560017, Karnataka, India

$\dagger$ Electronic supplementary information (ESI) available: Table showing polymerization details, plot of $I$ vs. scan rate. See DOI: $10.1039 / \mathrm{c} 8 \mathrm{ra} 06784 \mathrm{~h}$ adjustable micro supercapacitor system which further explores its feasibility to be integrated into miniaturized devices. ${ }^{7}$

Although the theoretical performance of these flexible energy storage devices is very high, their efficiency is extremely retarded owing to the assembly of various components in the device. This will greatly affect the commercialization of these portable electronic products. ${ }^{8}$ Hence intense care has to be taken for the development of efficient, flexible and high performance energy storage devices. Generally supercapacitors contain components such as electrodes, electrolytes, separators and current collectors. For the past two decades, enormous efforts have been made towards the development of nanostructured electrode materials. Qi Xue et al., demonstrated high stability and promising capacitance of the boron nanowires in all alkaline, neutral, and acid aqueous electrolytes. The prepared nanostructures integrated on a carbon fiber cloth substrate achieved a capacitance up to $60.2 \mathrm{mF} \mathrm{cm}^{-2}$. 9 These type of nanostructures can be integrated into the flexible substrates so as to enhance the properties through shortened diffusion length, superior specific surface area, enhance ion diffusion etc..$^{\mathbf{1 0 , 1 1}}$

In search of state-of-the art inexpensive, flexible, light weight, environmentally benign electrode materials, conductive polymer coated paper electrodes are receiving prominent scope of research interest among the scientific community. ${ }^{\mathbf{1 2 - 1 6}}$ The conventional flexible electrodes such as PET-ITO/FTO, metal foils, possess major drawbacks such as its production using 
highly sophisticated instrumentation, high cost for the precursor materials, time consuming process for the deposition, above all they are easily oxidized which can cause considerable drop in the electrical conductivity and the poor adhesion between the active layer. ${ }^{\mathbf{1 7 - 1 9}}$ Construction of paperbased supercapacitors with a reasonably good performance at a low price is highly beneficial, since paper is composed of large number of cellulose fibers/subnanofibrils with unique porous bulk structure along with rough and absorptive surface properties and high surface area. ${ }^{20-22}$ This may find advantageous as an electrode material for electrochemical systems. The main hindering thing is their high electrical surface resistivity of $10^{15}$ $\Omega \mathrm{sq}^{-1}$ which limits their potential applications in the electronics industry. However, prior surface modifications in the form of coating or growing nanostructured materials are required to make them electronically conductive. In this aspect, conductive polymer composites can easily be infused in the cellulose network; further which can be made-up into diverse shapes and sizes for its usage as working electrode..$^{23-25}$

Electrically conducting polymers such as polyaniline, polypyrrole is receiving interest since its conductivity can be tuned by controlling the reduction and oxidation process. The main draw back with conducting polymers based energy storage systems are its poor cycling stabilities and high self-discharge rates as well as mass transport limitation through the thick polymer mass. A promising strategy for solving this issue is either preparation of conducting polymers in nanoscale or depositing in a matrix with high surface area and porosity. ${ }^{26-29} \mathrm{~L}$ Yuan et al., designed PANI paper based supercapacitor electrodes for self-powdered nanosystems. The electrodes were prepared using conventional three component system through the oxidation of aniline onto a conducting gold coated paper. ${ }^{30}$ An aerial capacitance of $50 \mathrm{mF} \mathrm{cm} \mathrm{cm}^{-2}$ was reported. In another report by Cong et al., developed graphene-PANI paper based electrode for supercapacitor through a two step strategy which measured maximum specific capacitance of $763 \mathrm{~F} \mathrm{~g}^{-1} \cdot{ }^{31}$

Metal nanostructures such as copper, silver, gold are important materials for applications such as catalyst, optoelectronic devices due to their intrinsic properties which can be tailored with their nanosize and shape. Being highly conductive materials, silver has been the centre of attraction for the preparation of conductive nanomaterials. Silver nanoparticles have distinctive physicochemical and electrochemical properties including high chemical stability, catalytic activity etc. These properties make them of potential value in electronics, inks, and medical imaging etc. Several methods were reported for the preparation silver nanoparticles such as reduction of $\mathrm{Ag}^{+} \mathrm{using}$ chemical methods, template aided methods; electrochemical methods, photo reduction, and so forth. ${ }^{32,33}$

Thus development of conductive polymer-silver nanocomposite is receiving immense interest which stems from their synergistic physicochemical and electrochemical properties. Especially polyaniline-silver nanocomposites have received significant attraction because of their excellent biocompatibility, electro-catalytic and electro-chemical properties. ${ }^{34,35}$ Several strategies are reported for the preparation of polyaniline-silver nanocomposite like dispersion of silver nanoparticles on the surface of the polymer, in situ polymerisation of conductive monomer around the silver nanoparticles and reduction of silver ions using monomer as a reducing agent. ${ }^{36}$ A report by Ajay Singh et al., showed that free standing films of polypyrrole-silver nanocomposite films were used as electrode material for supercapacitors by photopolymerisation of pyrrole in presence of silver nitrate. ${ }^{37}$ From the aforementioned evidences, development of supercapacitors with excellent cycling stability, power and electron densities along with mechanical robustness and flexibility is receiving tremendous importance and subsequent fabrication of supercapacitor device of desired shape is therefore fascinating. So the present work envisages the preparation of conducting polyaniline decorated silver nanoparticle coated paper electrode and its characterization, demonstration as an efficient electrode for the fabrication of flexible and stable symmetrical supercapacitor.

\section{Experimental section}

\subsection{Materials}

Aniline, Ammonium persulphate (APS) and silver nitrate were purchased from Merck Limited, Mumbai, India. Polyvinylpyrrolidone (PVP) was purchased from Sigma Aldrich (Average M.W 10 000). All solvents used were analytical grade purchased from S.D fine chemicals. Printing paper was used for this experiment for electrode fabrication purpose.

\subsection{Preparation of nanosilver decorated polyaniline coated paper}

Silver nanoparticles were prepared by simple synthetic protocol as per the procedure given below.10 $\mathrm{ml}$ (in DMF) of $0.02 \mathrm{M}$ silver nitrate was dissolved in $10 \mathrm{ml}$ (DMF) of $0.1 \mathrm{M}$ PVP which was used as capping agent to provide colloidal stability of the resulting nanoparticles. Paper strip was cut into $2 \times 2 \mathrm{~cm}$ size and soaked into the above prepared $\mathrm{Ag}$ nanoparticle solution for $2 \mathrm{~h}$. The colour of the paper changed to shining yellow and then brown revealing the formation of silver nanoparticle on the surface of the paper. The $\mathrm{Ag}$ coated paper was dried at $60{ }^{\circ} \mathrm{C}$ for $1 \mathrm{~h}$ under vacuum. Then polymerization of aniline was carried out on the $\mathrm{Ag}$ coated paper substrate.

Polyaniline was deposited on the silver coated paper through polymerization of aniline using APS as oxidant initiator at ice cold conditions. Silver coated paper strip was soaked in aniline monomer for 5, 15, 30, 60 minutes and gently taken out using a forceps to obtain uniform coating on varying the amount of aniline onto the paper. These samples are designated as PAg1, PAg2, PAg3, and PAg4 respectively. Then the aniline coated paper was introduced in the oxidant initiator which was kept at ice cold conditions. Gradually brown colour changed into blue and then green as the polymerization time increased which confirmed the formation of polarons (conductive charges) in polyaniline. Then the paper was removed from the chamber and washed several times with distilled water and then $1 \mathrm{M} \mathrm{HCl}$. The conductivity of the films was optimized by the soaking time of aniline monomer and polymerization which is tabulated in Table 1 . This silver 
Table 1 Electrical conductivity, amount of PANI deposited and coating thickness on the silver paper electrode

\begin{tabular}{lcll}
\hline Sample & $\begin{array}{l}\text { Conductivity } \\
\left(\mathrm{S} \mathrm{cm}^{-1}\right)\end{array}$ & $\begin{array}{l}\text { Amount of PANI } \\
\text { deposited }(\mathrm{g})\end{array}$ & $\begin{array}{l}\text { Deposited coating } \\
\text { thickness of PANI (mm) }\end{array}$ \\
\hline PAg1 & 4.94 & 0.115 & 1.2 \\
PAg2 & 39.32 & 0.125 & 1.75 \\
PAg3 & 157.47 & 0.133 & 2.25 \\
PAg4 & 211.243 & 0.15 & 3 \\
PANI & 82.44 & 0.126 & 1.65
\end{tabular}

decorated PANI coated papers were demonstrated for the fabrication of symmetrical supercapacitors.

\subsection{Preparation of electrolytes}

Aqueous $\left(1 \mathrm{M} \mathrm{H}_{2} \mathrm{SO}_{4}\right)$ and PVA- $\mathrm{H}_{2} \mathrm{SO}_{4}$ based electrolytes were prepared for the fabrication of supercapacitors. Both the electrolytes were dipped in Whatman filter paper which acts as separator. $\mathrm{PVA}-\mathrm{H}_{2} \mathrm{SO}_{4}$ was prepared by dissolving PVA powder $(6 \mathrm{~g})$ in $60 \mathrm{~mL}$ deionised water containing $6 \mathrm{~g}$ of $\mathrm{H}_{2} \mathrm{SO}_{4}$.

\subsection{Fabrication of symmetrical supercapacitors}

Symmetrical supercapacitors were fabricated by sandwiching porous Whatmanfilter paper dipped in the respective electrolytes between two PAg paper electrodes. The electrochemical window, impedance, specific capacitance, energy density, power density, bending test and cycling stability of the fabricated supercapacitors were then evaluated using the cyclic voltammetry, impedance and galvanostatic charge-discharge measurements.

\section{Characterisation techniques}

The surface morphology of the samples coated on paper was studied mainly using various microscopic techniques such as SEM and AFM. Formation of silver nanoparticles formation was studied using TEM analysis. Zeiss EVO 18 cryo-scanning electron microscope (SEM) with variable pressure working at 20-30 $\mathrm{kV}$ was used for the SEM analysis. High-resolution transmission electron microscopy (HRTEM) was performed in an FEI TECNAI $\mathrm{S}$ Twin microscope with an accelerating voltage of $100 \mathrm{kV}$. For TEM measurements, the sample solutions were dispersed in the solvent and sonicated well under an ultrasonic vibrator. Then sample solutions were allowed to settle for a while and dropcasted the top solution on a Formvar-coated copper grid using micro pipette and dried at room temperature before observation. Atomic force microscopy (AFM) images were taken using a Bruker Multimode AFM-3COCF (Germany) operating in tapping mode. Particle size measurement of the samples were carried out in a Nano ZS Malvern instrument employing a $4 \mathrm{~mW}$ He-Ne laser $(I=632.8 \mathrm{~nm})$ and equipped with a thermostated sample chamber. X-ray diffraction studies were performed with an X-ray diffractometer (Philip's X'pert Pro) with $\mathrm{Cu}-\mathrm{K} \alpha$ radiation $(I=0.154 \mathrm{~nm})$ with the step size and scan rate of $0.02^{\circ}$ and $10^{\circ}$ per minute respectively employing an X'celerator detector and a monochromator at the diffraction beam side. Films were used by employing a standard sample holder. Cyclic and galvanostatic charge discharge (CV, GCD) studies and impedance analysis were carried out using a CHI6211B electrochemical analyzer, in which flexible paper electrode was used as working electrodes. The specific capacitance could be obtained from the slope of the discharge curve of the galvanostatic charging/ discharging mechanism according to eqn.

$$
C_{\mathrm{s}}=k i t / m \Delta v
$$

where $i$ is the current, $t$ is the elapsed time during the discharge process, $\Delta v$ is the total working potential, and $m$ is the mass of the electrode materials. Commonly, the formula includes the mass of the active materials. $k$ is a constant multiplier $(k=2$ if the mass of a single electrode is used and $k=4$ if the mass of both electrodes is taken into account). Electrochemical impedance measurements of the device were carried out in the frequency range of $0.1 \mathrm{~Hz}$ to $100 \mathrm{kHz}$ at a particular open-circuit potential. Electrical conductivity measurements of the paper electrodes were performed with a standard four-probe conductivity meter using a Keithley 6221 programmable current source and a 2128A nanovoltmeter. UV-vis absorption spectra of the samples were recorded using spectrophotometer (Shimadzu model 2100) in the range of $200-800 \mathrm{~nm}$.

\section{Results and discussion}

\subsection{Preparation of polyaniline-silver paper electrode (PAg)}

PANI-silver coated paper electrodes (PAg) were prepared by a two-step process involving initial silver nanoparticles coating followed by aniline polymerization over the paper as shown in Scheme 1. PAg paper electrodes were developed with varying amount of aniline by increasing the soaking time of aniline followed by polymerization time using APS as oxidative radical. Silver nanoparticles were prepared from silver nitrate through simple reduction using the solvent DMF in the presence of PVP which provides colloidal stability to the formed nanoparticles. DMF could perform as a reducing agent cum solvent for silver nanoparticles and is known for its superior stability in terms of chemically as well as thermally, and excellent solvent for a wide variety of organic and inorganic materials. ${ }^{38,39}$

The size of the prepared silver nanoparticles was measured using TEM and particle size analyser (Fig. 1a, b and d, HRTEM is shown in Fig. S1†). TEM analysis confirmed the formation of uniform spherical silver nanoparticles of average size around 10-20 nm, which was further conformed from DLS measurements. HRTEM showed the fringes corresponding to $d$ spacing of $0.237 \mathrm{~nm}$ which is indexed to 111 plane of silver nanoparticles (Fig. 1b). The prepared nanosilver could be indexed for the face-centered cubic (fcc) structure which was confirmed from SAED (Fig. 1c) and further strengthened from XRD pattern which is being discussed below. PAg paper electrodes were prepared with varying amount of aniline and polymerization time are designated as PAg1, PAg2, PAG3, and PAG4 respectively. The electrical conductivity of PAg films with varying amount of aniline loading and the experimental details are 


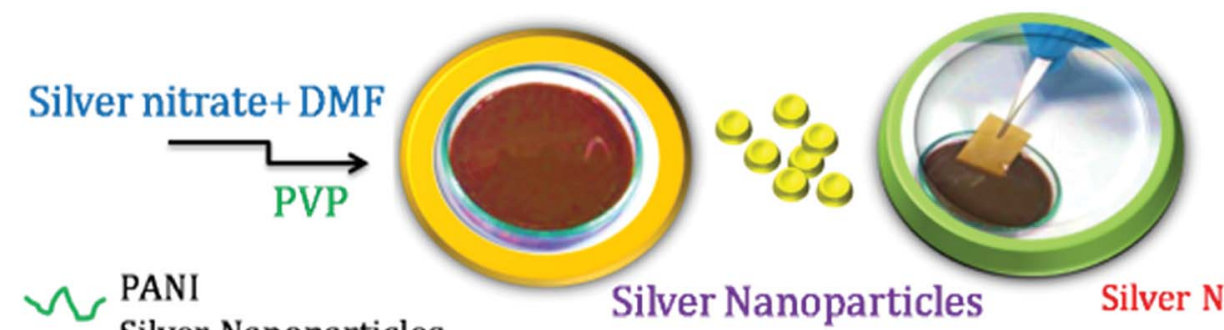

Silver Nanoparticles

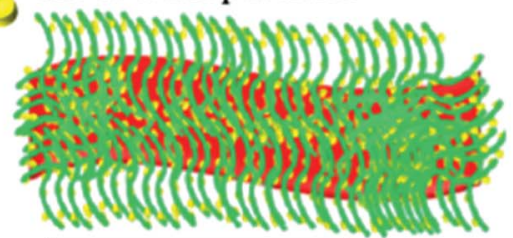

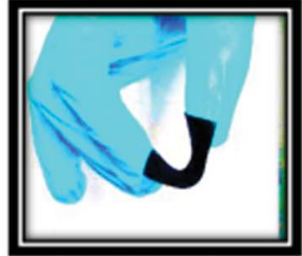

Flexible PAg Electrode

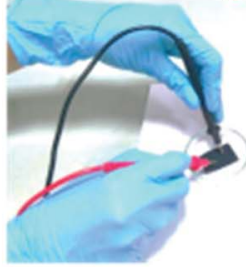

Electrical Conductivity of Paper

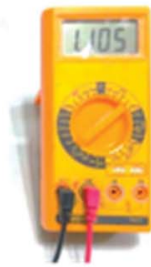

PAg<smiles>CC1CCCCC1</smiles>

Polymerisation

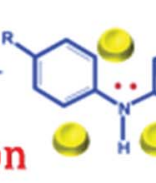<smiles>C1CCC2CCCCC2C1</smiles>

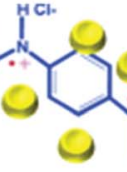

$+\mathrm{HC}+\mathrm{H}_{2} \mathrm{SO}_{4}+\mathrm{NH}_{4} \mathrm{SO}_{4}$

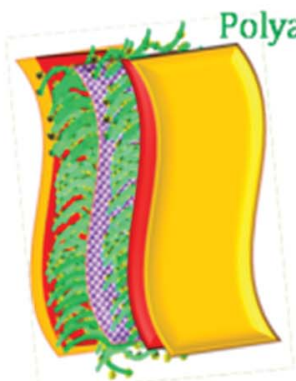

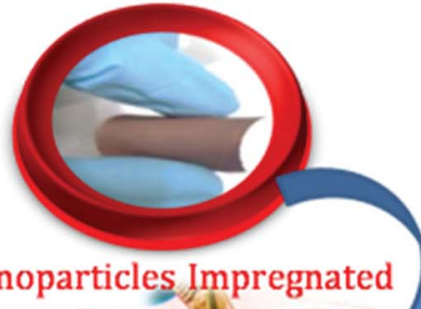

Paper

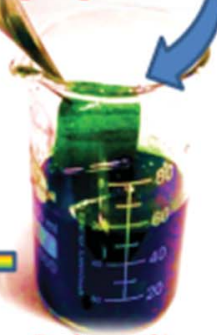

Polyaniline

Formation over

Silver Paper

Scheme 1 Formation of silver stacked PANI based paper electrodes.
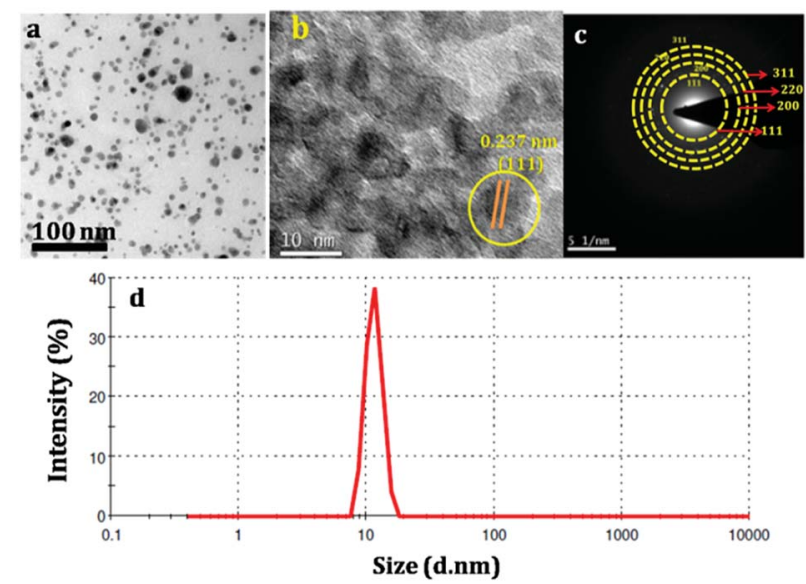

Fig. 1 ( $a$ and b) TEM and HRTEM of silver nanoparticles, (c) SAED Pattern of silver nanoparticles (d) DLS analysis of silver nanoparticles for particle size measurement.

given in the ESI as Table S1. $\dagger$ Electrical conductivities of the prepared PAg's were measured using four probe electrical conductivity meter (Fig. 2). Figure shows the effect of mass loading vs. conductivity when moving from PAg1 to PAg4.
The measured conductivity values were found to be increasing from 4.94, 39.23, 157.47, $211.24 \mathrm{~S} \mathrm{~cm}^{-1}$ for PAg1, PAg2, PAg3, and PAg4, respectively. The percolation region was found to be at PAg3 where the conductivity increased drastically beyond which the percolation was achieved. ${ }^{40}$

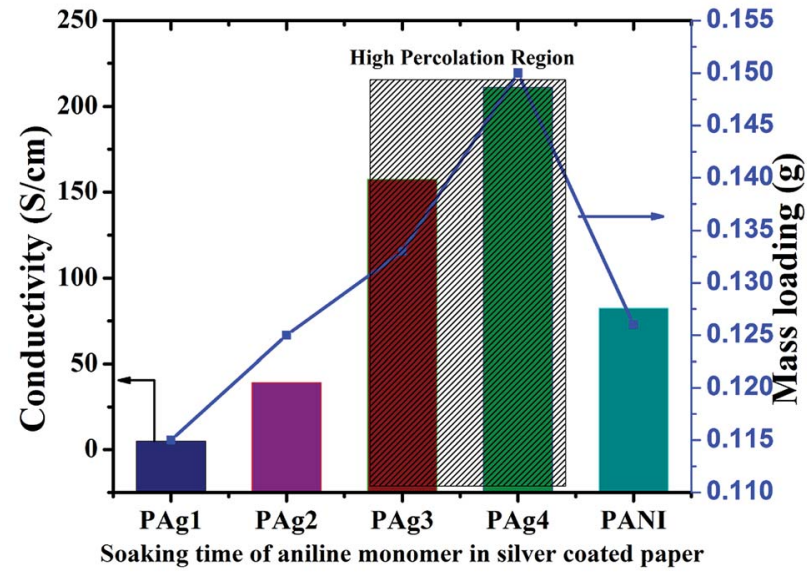

Fig. 2 Electrical conductivity of PANI coated on silver paper for different time intervals. 
PAg4 decorated with silver PANI nanowire network exhibited highest conductivity $\left(211.24 \mathrm{~S} \mathrm{~cm}^{-1}\right)$, which is mainly attributed to the uniform silver stacking in the paper thereby providing smooth conducting channels through conductive PANI for efficient electron transport. PANI alone exhibited a conductivity of $82.44 \mathrm{~S} \mathrm{~cm}^{-1}$. The approximate PANI deposition of the PAg4 was measured to be around $0.15 \mathrm{~g}$. The bare paper was weighed to be less than $0.1 \mathrm{~g}$.

The amount of PANI deposited onto the silver paper increased from $0.1 \mathrm{~mm}$ to $0.15 \mathrm{~mm}$ which corresponds to the uniform coating of PANI upon polymerization for various time intervals. The coating thickness on the silver paper was measured and found to be around $2.25 \mathrm{~mm}$ for PAg4. The details are tabulated in Table 1 . The conductivity of the PAg electrode at different bending curvature was measured using the four probe conductivity analysis (ESI $\dagger$ ). The electrodes were mechanically stable at different bending curvatures and it is measured the surface conductivity (208 and $\left.210 \mathrm{~S} \mathrm{~cm}^{-1}\right)$ at various different bending states, revealing the performance of the PAg electrode is hardly influenced by external stress. PAg4 was optimized as the electrode material for the fabrication of supercapacitor due to its high conductivity.

The opto-electronic properties of the prepared silver nanoparticles, PANI and PAG4 were studied by UV-vis spectroscopy. The UV-vis spectra of pure PANI, Ag and PAg4 nanocomposite are shown in Fig. 3a-c respectively. UV-vis spectra of Ag nanoparticles showed absorption maxima at 400-417 $\mathrm{nm}$ corresponding to the surface plasmon resonance energy of the silver nanoparticles. The spectra showed more intense and sharper band which is attributed to the existence of more uniform silver nanoparticles. PANI exhibited spectral maxima at $329 \mathrm{~nm}$ and $637 \mathrm{~nm}$ associated with $\pi-\pi^{*}$ transitions of the benzenoid structure and $n-\pi *$ transitions of the quinonoid ring, respectively. In comparison with PANI, the peaks at $370 \mathrm{~nm}$ and $637 \mathrm{~nm}$ are shifted to $390 \mathrm{~nm}$ and $750 \mathrm{~nm}$ in PAg4 composite, respectively. These changes are related to the presence of more intense polar band generated by the presence of interaction

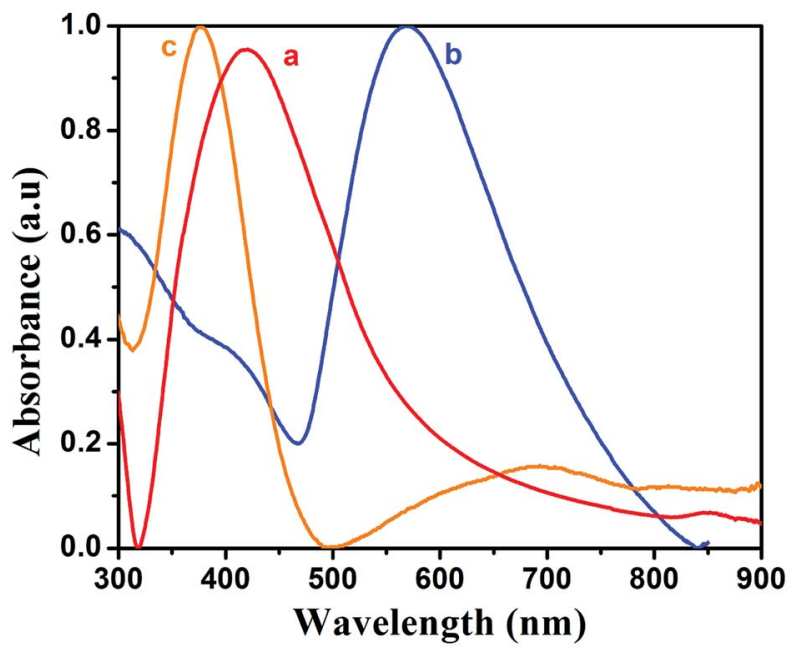

Fig. 3 UV-vis spectra of (a) silver, (b) PANI, (c) PAg4. between polyaniline chain and silver nanoparticles. Due to the electrostatic interaction, silver atoms have a large amount of free electrons. These free electrons can easily conjugate with the nitrogen atoms from benzenoid and quinonoid structures of PANI chains. Once the conducting PANI gets impregnated with silver nanoparticles, a conjugating electron cloud between these is formed easily, resulting in a red-shift in UV-vis spectra of PAg nanocomposite. The presence of these formed polarons is expected to for the high conductivity and further enhances the performance of the supercapacitor device. ${ }^{41-43}$

Morphology of paper coated with silver nanoparticles, PANI and PAg4 coated on paper were studied by SEM and AFM. Typical SEM and AFM image silver nanoparticles are shown in Fig. 4a and b, respectively. PANI nanowires with a diameter of about 100-200 nm were observed to be knotted and wrapped with each other, which leads to the patterning of uniform and highly porous interconnected networks on paper. SEM and AFM of the same are shown Fig. 4c, d and S2, $\uparrow$ respectively. The height profile of the same is shown in Fig. S3. $\dagger$ These highly porous PANI network arrangements can drastically improve the supercapacitor performance through efficient uptake of electrolyte, and can also act as an effective pathway in shuttling ion transportation between the PANI and electrolyte. SEM and AFM of PAg4 coated on paper is shown in Fig. $4 \mathrm{e}-\mathrm{g}$, respectively. It can be seen that silver nanoparticles are beautifully festooned on the surface of PANI wires. The average diameter of the Ag nanoparticles were about $10-20 \mathrm{~nm}$. The highly monodispersed silver nanoparticles with good dispersion with the polymer matrix is expected to provide a high charge/discharge rate and thus enhancing the specific capacitance of the device. The Ag nanoparticles play a vital role in decreasing the internal resistance and thereby enhancing the electronic conductivity of the paper electrode. Further these Ag nanoparticles can induce the
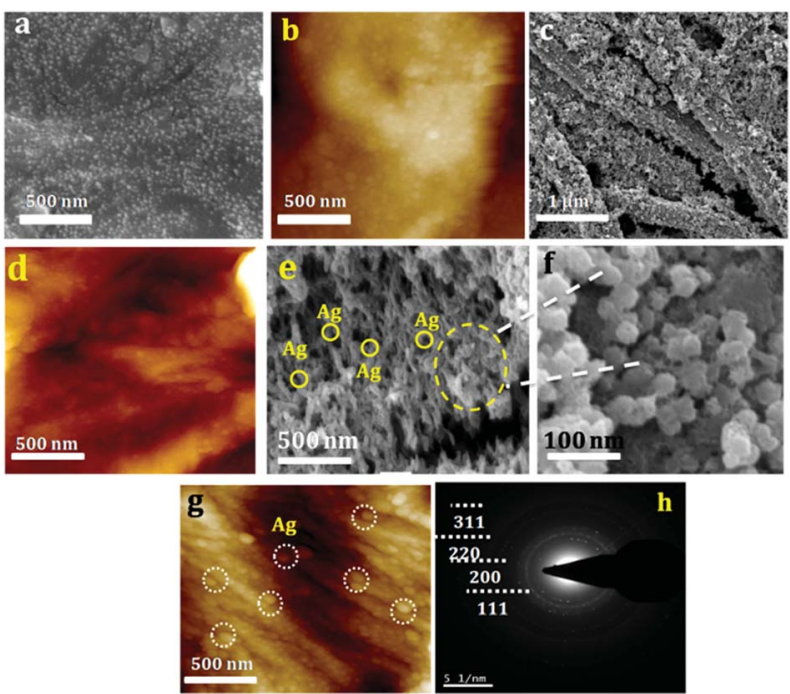

Fig. 4 ( $a$ and $b$ ) SEM and AFM of silver nanoparticles coated on paper, (c and d) SEM and AFM of PANI nanowires coated on paper $(e-g)$ SEM and AFM of PANI nanowires embedded with silver nanoparticles coated on paper (h) SAED pattern of PAg. 
ordering of the PANI chains through the interchain linkage to efficiently bind with nitrogen sites of PANI chains.

The SAED patterns of PAg are shown in Fig. 4h. The concentric rings corresponds to the diffraction pattern of the $\mathrm{Ag}$ nanoparticles confirms its polycrystalline nature of the composite. The rings arise because of the reflections from (111), (200), (220), and (311) lattice planes of fcc Ag. Further, crystalline phase and crystallinity of silver particles and PAg were confirmed by XRD.

The XRD patterns of pure Ag, PANI, and PAg4 are shown in Fig. 5. Pure PANI exhibited broad diffractograms in the range of $2 \theta=10^{\circ}-30^{\circ}$ which is mainly attributed to the parallel and perpendicular periodicity of the PANI chain (Fig. 5a). The broad diffractogram observed at $\sim 2 \theta=19.3^{\circ}$ and $2 \theta=25.7^{\circ}$ corresponding to the $d$ spacing value of $4.593 \AA$ and $3.461 \AA$, respectively. The broadness of the diffractogram represents the low crystallinity of the PANI which is mainly due to change in the configuration of the repeated of benzenoid and quinoid rings in PANI chain. X-ray diffraction analysis of silver nanoparticles presented distinct peaks corresponding to the lattice planes of fcc of silver nanoparticles that could be indexed for the face-centered-cubic (fcc) structure of silver (Fig. 5b). The peaks positioned at $38.22,44.35,64.48$, and $77.50^{\circ}$ can be related with the (111), (200), (220), and (311) $h k l$ values of facecentered-cubic silver nanoparticles. The SAED patterns also showed quite similar, to that of X-ray diffraction patterns which further strengthened the formation of silver nanoparticles. The average crystallite size of the Ag nanoparticle calculated using Scherrer's equation is $25 \mathrm{~nm}^{\mathbf{4 4}}$

For the PAg, the sharp diffractograms at $2 \theta$ values of $38.10^{\circ}$, $53.28^{\circ}, 64.44^{\circ}$ corresponded to the face-centered cubic (fcc) phase of silver (111), (142), and (220), respectively (Fig. 5c). The existence of sharp peaks in PAg clearly indicates the presence of fcc crystalline phase of nanoparticles in the nanocomposite with their crystalline nature.

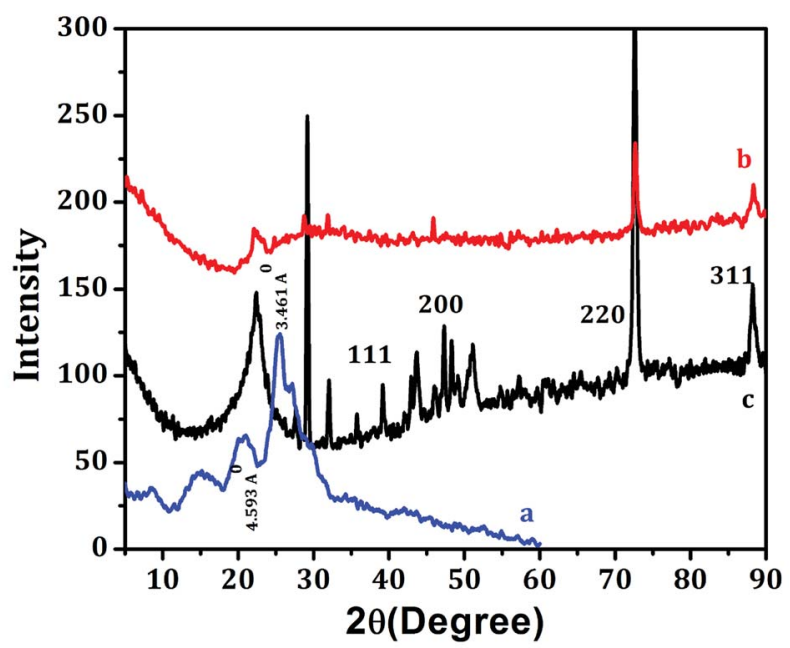

Fig. 5 XRD analysis of (a) PANI, (b) Ag nanoparticles, (c) PAg4. All the $X R D$ were taken after coating on the paper.

\subsection{Electrochemical characteristics of the paper based electrodes}

The electroactive surface area of the paper electrode was measured using cyclic voltammetry by studying the effect of scan rate as a function of variation in anodic peak current. Fig. $\mathrm{S} 4 \uparrow$ shows the plot peak current $v s$. square root of scan rate which showed a linear relationship, indicating that the current linearly increases with the scan rate. The correlation coefficient was found to be 0.990 . The electroactive surface area was calculated using Randles-Sevcik equation (eqn (1)) from the plot of peak current $I_{\mathrm{p}}$ versus the square root of scan rate,

$$
I_{\mathrm{pa}}=2.68 \times 10^{-5} n^{1 / 2} A C_{0} D \nu^{1 / 2}
$$

where $I_{\mathrm{pa}}$ represents to the anodic peak current $(A), n$ is the number of electrons involved, $A$ is area of the electrode $\left(\mathrm{cm}^{2}\right), D$ is the diffusion coefficient, $C_{0}$ is the concentration of electrolyte, and $\nu$ is the scan rate. The effective electro active surface area can be calculated from the slope of the plot of $I_{\mathrm{pa}} v s . \nu^{1 / 2}$ and it was found to be $0.152 \mathrm{~cm}^{2}$ for PAg4 electrode. The superior electro-active surface area of the electrode proposes itself as a promising candidate as electrode material which is assumed to provide more efficient electroactive sites.

Flexible supercapacitors were prepared by sandwiching the PANI and PAg4 coated paper electrodes in between the electrolytes bloated filter paper. The electrolytes used are aqueous $1 \mathrm{M} \mathrm{H}_{2} \mathrm{SO}_{4}$ and PVA- $\mathrm{H}_{2} \mathrm{SO}_{4}$ gel electrolytes. The electrochemical window stability of the supercapacitor device $\left(\mathrm{PANI} / \mathrm{H}_{2} \mathrm{SO}_{4} /\right.$ PANI and $\mathrm{PAg} / \mathrm{H}_{2} \mathrm{SO}_{4} / \mathrm{PAg}$ ) was studied by cyclic voltammetric technique. The extent of the stability of the electrochemical potential window is considered to be very important and there exists a stern concern in aqueous electrolytes where increasing the potential window beyond $1.2 \mathrm{~V}$ induces oxygen/hydrogen evolution i.e. water decomposition and thereby leading to the damage of the device.

Henceforth, in order to further enhance the potential window, we have measured the performance of the device in gel
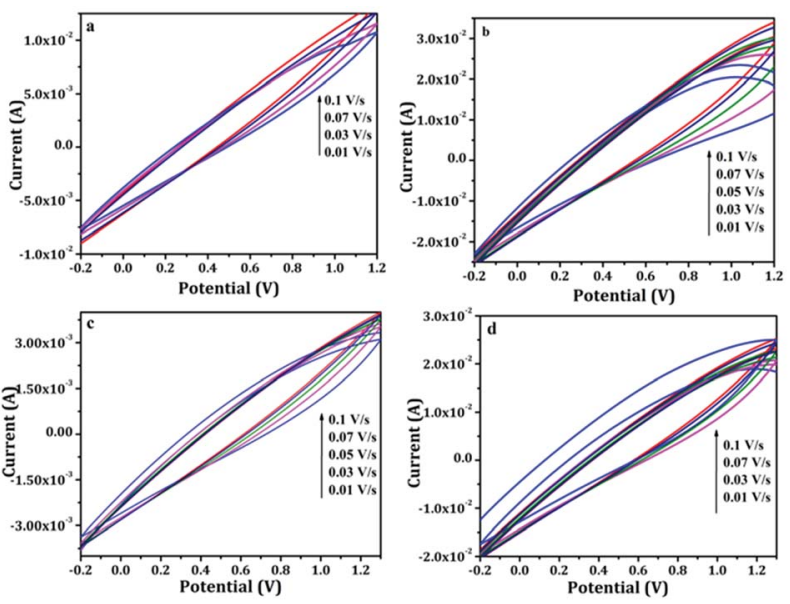

Fig. 6 Cyclic voltammograms of ( $a$ and b) PANI/1 $\mathrm{M} \mathrm{H}_{2} \mathrm{SO}_{4} / \mathrm{PANI}$ and PAg4/1 $\mathrm{M} \mathrm{H}_{2} \mathrm{SO}_{4} / \mathrm{PAg} 4$ in aqueous electrolyte, (c and d) PANI/PVA$\mathrm{H}_{2} \mathrm{SO}_{4} / \mathrm{PANI}$ and PAg4/PVA- $\mathrm{H}_{2} \mathrm{SO}_{4} / \mathrm{PAg} 4$ in gel electrolyte. 
electrolyte apart from the aqueous electrolyte. In the gel electrolyte system, the potential range was measure upto $1.3 \mathrm{~V}$, in which the paper based supercapacitor system showed an improvement in the device efficiency. Fig. 6a-d shows the cyclic voltammograms measurements recorded using two-electrode system with a voltage window ranging from -0.2 to $1.2 \mathrm{~V}$ in aqueous electrolyte and -0.2 to $1.3 \mathrm{~V}$ in gel polymer electrolyte. Generally all of the CV exhibited a stable electrochemical voltammograms $(-0.2$ to $1.2 \mathrm{~V})$ with a hike in the current with increasing scan rates $\left(0.01\right.$ to $\left.0.1 \mathrm{~V} \mathrm{~s}^{-1}\right)$. The redox current increased from $0.01 \mathrm{~A}$ to $0.03 \mathrm{~A}$ in the case of PANI and PAg4 device in aqueous electrolytes (Fig. 6a and b). Similarly in the case of gel electrolyte, PANI and PAg4 devices exhibiting a redox current of $3 \mathrm{~mA}$ and 0.03 A respectively (Fig. $6 \mathrm{c}$ and d). The increase in the redox current showed the highly conducting nature of PAg4 based electrodes which are mainly related to the uniform dispersion PANI nanowire like network onto the silver paper electrodes thereby further providing more effective surface area that could facilitate for the easy access for the electrolytes. This effect exemplifies the good electrochemical performance of the paper electrodes. ${ }^{45}$

Electrochemical impedance spectroscopic studies were carried out to analyze the charge transfer mechanism taking place between the electrode and the electrolyte. Fig. 7A and B shows the impedance Nyquist plots of PANI and PAg4 electrode based device in aqueous and gel electrolytes respectively. Electrochemical impedance spectroscopy (EIS) is a non-destructive steady-state technique useful to probe electron transfer and the mechanism of charge conduction process at the electrode/ electrolyte interface by applying an oscillating potential as a function of frequency device. The complex impedance $(Z)$ can be presented as a sum of the real impedance $\left(Z^{\prime}(\Omega)\right)$ and imaginary impedance $\left(Z^{\prime \prime}(\Omega)\right)$, which are components that originate mainly from the resistance and capacitance of the device.

$$
Z=Z^{\prime}-i Z^{\prime \prime}
$$

Typical electrochemical impedance spectrum can be presented in the form of Nyquist plots, $Z^{\prime \prime} v s . Z^{\prime}$ which is recorded as a function of frequency.

$$
|Z|=\left[\left(Z^{\prime}\right)^{2}+\left(Z^{\prime \prime}\right)^{2}\right]^{1 / 2}
$$
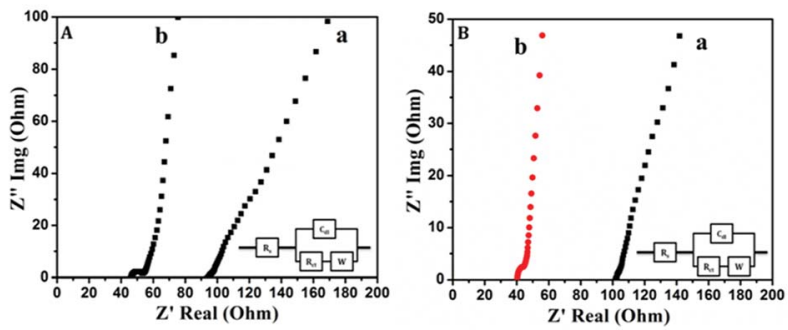

Fig. 7 Electrochemical impedance spectra of (A) (a) PANI/1 $\mathrm{M} \mathrm{H}_{2} \mathrm{SO}_{4} /$ PANI and (b) PAg4/1 $\mathrm{M} \mathrm{H}_{2} \mathrm{SO}_{4} / \mathrm{PAg} 4$ in aqueous electrolyte, (B) (a) $\mathrm{PANI} / \mathrm{PVA}-\mathrm{H}_{2} \mathrm{SO}_{4} / \mathrm{PANI}$ and (b) PAg4/PVA- $\mathrm{H}_{2} \mathrm{SO}_{4} / \mathrm{PAg} 4$ in gel electrolyte. Inset shows the corresponding equivalent circuit diagram.
Generally, Nyquist plot includes three regions: a nearly vertical line at low frequencies characterized by capacitive behaviour, a nearly diagonal line at intermediate frequencies related to diffusion resistance, and a semicircle at high frequencies presenting the charge transfer resistance. The device in aqueous electrolytes exhibited a small semicircle followed by a straight line with a $R_{\text {ct }}$ of $140 \Omega$ and $70 \Omega$ for PANI and PAg respectively representing the characteristics of a diffusion limited electron-transfer process on the electrode surface. ${ }^{46}$ The plot shows a semicircle followed by a Warburg line.

Similarly, the device in gel electrolytes exhibited a similar trend with a $R_{\mathrm{ct}}$ of $140 \Omega$ and $55 \Omega$ for PANI and PAg4 respectively. ${ }^{46}$ In both the cases the PANI electrode based device exhibited a larger semicircular arc compared to the PAg4 based device which represents an interfacial resistance due to the electrostatic repulsion on the surface of the electrode and electrolyte interface. The plot at the low frequency region was almost vertical close to $\sim 90^{\circ}$ which further suggested that the PAg4 demonstrated a diffusion controlled Warburg capacitive behaviour. This resulted in higher electron transfer resistance for PANI based devices. The inset displays the equivalent circuit (Randles model) used to fit the Nyquist diagrams, which consists of a solution resistance $R_{\mathrm{S}}$ connected in series with the double layer capacitance $\left(C_{\mathrm{dl}}\right)$, charge transfer resistance $\left(R_{\mathrm{ct}}\right)$, and Warburg impedance $\left(Z_{\mathrm{w}}\right)$, respectively. ${ }^{\mathbf{4 0}}$

The specific capacitance of the supercapacitors at current density of $5 \mathrm{~mA} \mathrm{~g}^{-1}$ were evaluated from the galvanostatic charge/discharge using eqn (2) given below.

$$
C_{\mathrm{s}}=4 I \Delta t / m \Delta V
$$

where $C_{\mathrm{s}}$ was specific capacitance, $I$ is the current $\left(5 \mathrm{~mA} \mathrm{~g}^{-1}\right), \Delta t$ is the discharge time, $\Delta V$ is the voltage window $(1 \mathrm{~V})$, and $m$ is the mass of electroactive material coated onto the electrode. ${ }^{47-50}$
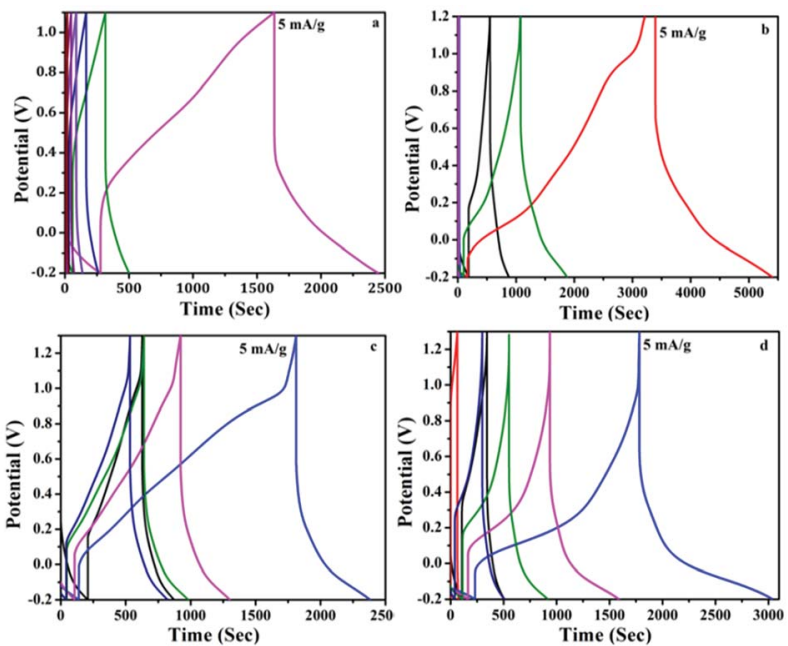

Fig. 8 Galvanostatic charge/discharge profiles of (a) PANI/1 $\mathrm{M} \mathrm{H}_{2} \mathrm{SO}_{4}$ / PANI and (b) PAg4/1 $\mathrm{M} \mathrm{H}_{2} \mathrm{SO}_{4} / \mathrm{PAg} 4$ in aqueous electrolyte, (c) PANI/ $\mathrm{PVA}-\mathrm{H}_{2} \mathrm{SO}_{4} / \mathrm{PANI}$ and (d) PAg4/PVA $-\mathrm{H}_{2} \mathrm{SO}_{4} / \mathrm{PAg} 4$ in gel electrolyte (all the measurements were taken at a current density of $5 \mathrm{~mA} \mathrm{~g}^{-1}$ ). 
Table 2 Device properties of PANI and PAg4 in $1 \mathrm{M} \mathrm{H}_{2} \mathrm{SO}_{4}$ aqueous and PVA- $\mathrm{H}_{2} \mathrm{SO}_{4}$ gel electrolytes

\begin{tabular}{|c|c|c|c|c|c|}
\hline Sample and electrolyte & Potential (V) & $\begin{array}{l}\text { Current } \\
\left(\mathrm{A} \mathrm{g}^{-1}\right)\end{array}$ & $\begin{array}{l}\text { Specific capacitance } \\
\left(\mathrm{F} \mathrm{g}^{-1}\right)\end{array}$ & $\begin{array}{l}\text { Energy density } \\
\left(\mathrm{W} \mathrm{h} \mathrm{kg}^{-1}\right)\end{array}$ & $\begin{array}{l}\text { Power density } \\
\left(\mathrm{W} \mathrm{kg}^{-1}\right)\end{array}$ \\
\hline PANI $\left(1 \mathrm{M} \mathrm{H}_{2} \mathrm{SO}_{4}\right)$ & -0.2 to 1.2 & 5 & 467 & 64.86 & 130.82 \\
\hline PANI (PVA- $\left.\mathrm{H}_{2} \mathrm{SO}_{4}\right)$ & -0.2 to 1.3 & 5 & 213 & 29.58 & 119.13 \\
\hline PAg $\left(1 \mathrm{M} \mathrm{H}_{2} \mathrm{SO}_{4}\right)$ & -0.2 to 1.2 & 5 & 483 & 69.56 & 243.44 \\
\hline PAg $\left(\mathrm{PVA}-\mathrm{H}_{2} \mathrm{SO}_{4}\right)$ & -0.2 to 1.3 & 5 & 613 & 85.13 & 405.37 \\
\hline
\end{tabular}

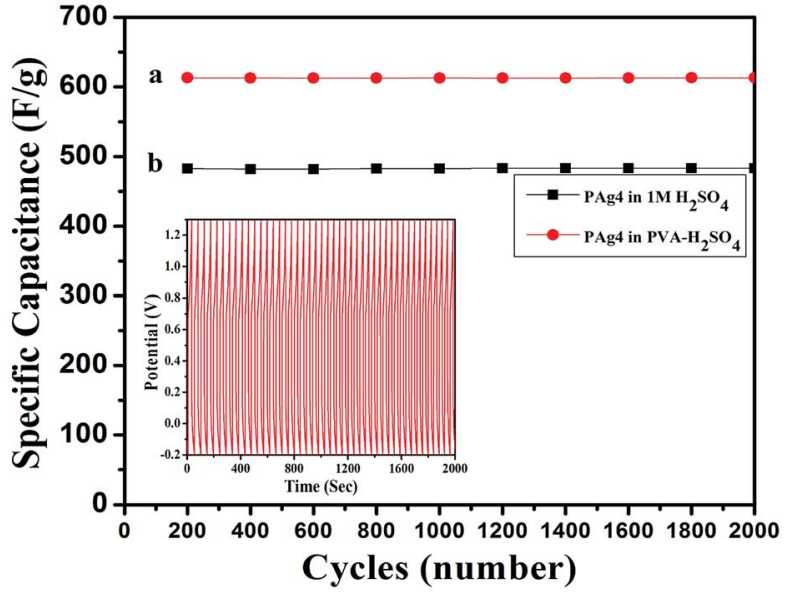

Fig. 9 Cyclic stability of (a) PAg4 in $1 \mathrm{M} \mathrm{H}_{2} \mathrm{SO}_{4}$, (b) PAg4 in PVA$\mathrm{H}_{2} \mathrm{SO}_{4}$.

Fig. 8a-d shows the charge/discharge profile of PANI and PAg4 based devices in aqueous electrolyte. The stable symmetric charge/discharge curves exhibited by the cells entails that their electrochemical behaviour originates from the typical pseudocapacitance nature of conductive PANI and high electronic properties of the ordered silver nanoparticles.
The details of the various parameters calculated for the device is listed in Table 2. The drop in the internal resistance (IR) for PANI based systems elucidates the presence of internal series resistance, which measured the capacitance as 467 and $213 \mathrm{~F} \mathrm{~g}^{-1}$ in aqueous and gel electrolytes respectively. However PAg4 coated electrodes showed higher specific capacitances of 483 and $613 \mathrm{~F} \mathrm{~g} \mathrm{~g}^{-1}$ in the aqueous and gel electrolytes respectively. In both the cases the discharge current is $5 \mathrm{~mA}$. During the charging and discharging period, the conducting silver nanoparticles facilitates the electron transfer and the pseudo capacitive behaviour of PANI enhances the capacitance overall, which can be attributed to the synergetic effect of the composite electrode. Further, the high conductivity on the surface of the electrode will permit huge number of ions to flow freely after the adsorption of electrolyte by the electrodes, which further facilitates towards the rapid shuttling of the ions in the active species, by providing a smooth pathway through the nanostructured particles for the efficient transport of electrons. The final device weighed about less than $0.5 \mathrm{~g}$ which illustrates its very light weight nature, further which can be used for its commercialization.

The specific energy density and power density were calculated using the eqn (3) and (4).

$$
E=\frac{C V^{2}}{2 \times 3.6}
$$

Table 3 Comparison of properties of flexible paper based hybrid supercapacitor systems

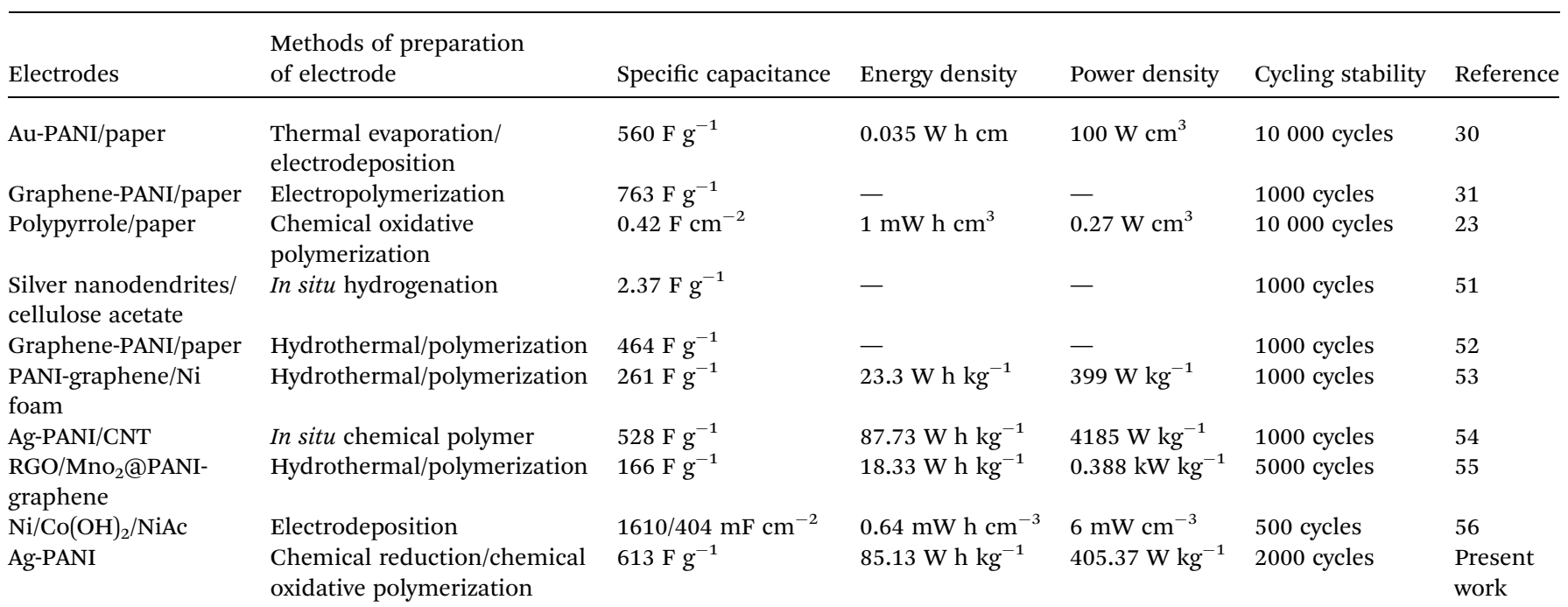




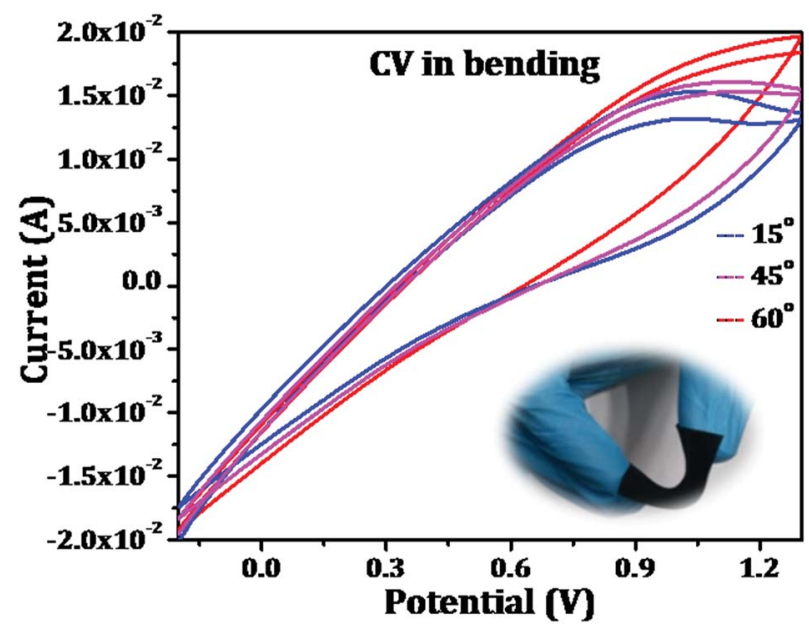

Fig. 10 Cyclic voltammetry of PAg in $\mathrm{PVA}-\mathrm{H}_{2} \mathrm{SO}_{4}$ under different bending angles.

$$
P=\frac{E}{t} \times 3600
$$

The symmetric supercapacitor device of PANI electrodes revealed an energy density of $64.86 \mathrm{~W} \mathrm{~h} \mathrm{~kg}^{-1}$ and $29.58 \mathrm{~W} \mathrm{~h} \mathrm{~kg}^{-1}$ in $\mathrm{H}_{2} \mathrm{SO}_{4}$ and $\mathrm{PVA}-\mathrm{H}_{2} \mathrm{SO}_{4}$ respectively while that of device prepared with PAg electrodes showed 67.08 and $85.13 \mathrm{~W} \mathrm{~h} \mathrm{~kg}^{-1}$ respectively. Similarly the power density of the device with PANI electrodes was measured to be 119.13 and $130.82 \mathrm{~W} \mathrm{~kg}^{-1}$ and that of PAg device exhibited very high power density of 243.44 and $405.375 \mathrm{~W} \mathrm{~kg}^{-1}$ in $\mathrm{H}_{2} \mathrm{SO}_{4}$ and $\mathrm{PVA}_{-} \mathrm{H}_{2} \mathrm{SO}_{4}$ electrolytes respectively at $5 \mathrm{~mA} \mathrm{~g}^{-1}$ current density. The higher diffusion conductance of ions through the porous structures is the sole reason for enhancing the power density for PAg based electrodes. This high performance of the device exhibited in solid electrolytes can be endorsed to their exceptional property of the electrodes which exhibited network like nanostructures and its associated high electrical conductivity of PANI networks arising from the silver nanoparticles.

The cyclic stability of device is a very important property to be evaluated for testing the performance of flexible device. The PAg4 based device was subjected to 2000 cycles for measuring the cyclic stability using GCD. The cell measured about $85 \%$ retention in its specific capacitance and the results are shown in Fig. 9.

The measured high specific capacitance of PAg4 based devices in gel electrolyte when compared with its aqueous counterparts is mainly ascribed to the fast and efficient faradic reactions happening in the PANI networks in the presence of highly conducting silver nanoparticles as compared to pure PANI. The reduction in the internal resistance produces charge carriers within the conducting networks due to which is the cells based on PAg4 measured higher performance. A comparison of the performance of various paper based supercapacitor devices is shown in Table 3.

Further, the mechanical flexibility of the as-fabricated symmetrical supercapacitors was evaluated by making the device through different angles of bending. The results are shown in Fig. 10 which represents the capacitive behaviour of the device was retained which confirms that the flexible device has excellent mechanical deformation capability. All these results evidence its application in flexible electronic gadgets and performances are to be evaluated.

\section{Conclusion}

In conclusion, we have successfully developed a sustainable facile strategy for the fabrication of low cost, highly flexible and high-performance supercapacitors based on silver nanoparticle decorated PANI nanowires coated printing paper electrode. The silver nanoparticles of 10-20 nm decorated with PANI networks based paper electrode measured an electrical conductivity of $211 \mathrm{~S} \mathrm{~cm}^{-1}$. Further fabricated supercapacitor device which showed specific capacitance of $613 \mathrm{~F} \mathrm{~g}^{-1}$, electron density (85.13 $\mathrm{W} \mathrm{h} \mathrm{kg}^{-1}$ and power density $405.37 \mathrm{~W} \mathrm{~kg}^{-1}$ ) and cycling stability $(90 \%$ of its capacitance retention even after 2000 cycles). The prepared supercapacitor exploited for lighting LED bulb. All these excellent properties of this sustainable flexible supercapacitor open up new window for the fabrication of flexible and wearable energy storage devices for integrating with flexible electronic gadgets.

\section{Conflicts of interest}

There are no conflicts to declare.

\section{Acknowledgements}

We are thankful for the financial support from ISRO RESPOND project GAP 137039. We are thankful to Dr A. Ajayaghosh, Director, CSIR-NIIST, Trivandrum for constant encouragement and support. We are also thankful to Mr Kiran Mohan, $\mathrm{Mr}$ Harish Raj V, Mr Vibhu, and Dr P. Prabhakar Rao for SEM, TEM, AFM and XRD analyses.

\section{References}

1 P. Simon and Y. Gogotsi, Nat. Mater., 2008, 7, 845, DOI: 10.1038/nmat2297.

2 J. R. Miller and P. Simon, Science, 2008, 321, 651, DOI: 10.1126/science.1158736.

3 M. Winter and R. J. Brodd, Chem. Rev., 2005, 105, 1021, DOI: 10.1021/cr040110e.

4 C. Liu, F. Li, L. P. Ma and H. M. Cheng, Adv. Mater., 2010, 22, 28, DOI: 10.1002/adma.200903328.

5 Y. P. Fu, X. Cai, H. W. Wu, Z. B. Lv, S. C. Hou, M. Peng, X. Yu and D. C. Zou, Adv. Mater., 2012, 24, 5713, DOI: 10.1002/ adma.201202930.

6 C. Largeot, C. Portet, J. Chmiola, P. L. Taberna, Y. Gogotsi and P. Simon, J. Am. Chem. Soc., 2008, 130, 2730, DOI: 10.1021/ja7106178.

7 M. Zhu, Y. Huang, Y. Huang, H. Li, Z. Wang, Z. Pei, Q. Xue, H. Geng and C. Zhi, Adv. Mater., 2017, 29, 1605137, DOI: 10.1002/adma.201605137. 
8 L. Li, Z. Wu, S. Yuan and X.-B. Zhang, Energy Environ. Sci., 2014, 7, 2101, DOI: 10.1039/c4ee00318g.

9 Q. Xue, H. Gan, Y. Huang, M. Zhu, Z. Pei, H. Li, S. Deng, F. Liu and C. Zhi, Adv. Energy Mater., 2018, 8, 1703117, DOI: $10.1002 /$ aenm.201703117.

10 G. Wang, L. Zhang and J. Zhang, Chem. Soc. Rev., 2012, 41, 797, DOI: 10.1039/c1cs15060j.

11 B. E. Conway, Electrochemical Supercapacitors: Scientific Fundamentals and Technological Applications, Kluwer Academic/Plenum Press, New York, 1999, ISBN 978-1-47573060-9. DOI: 10.1007/978-1-4757-3058-6.

12 C. A. Amarnath, J. H. Chang, D. Kim, R. S. Mane, S.-H. Han and D. Sohn, Mater. Chem. Phys., 2009, 113, 14, DOI: 10.1016/ j.matchemphys.2008.08.068.

13 H. Zhang, Q. Zhao, S. Zhou, N. Liu, X. Wang, J. Li, et al., J. Power Sources, 2011, 196, 10484, DOI: 10.1016/ j.jpowsour.2011.08.066.

14 J. H. Park and O. O. Park, J. Power Sources, 2002, 111, 185, DOI: 10.1016/S0378-7753(02)00304-X.

15 K. R. Prasad and N. Munichandraiah, J. Power Sources, 2002, 112, 443, DOI: 10.1016/S0378-7753(02)00419-6.

16 I. Shown, A. Ganguly, L. Chyong Chen, K. Hsien Chen, 2015; 3, 2. DOI: 10.1002/ese3.50.

17 M. Hiramatsu, K. Imaeda, N. Horio and M. Nawata, J. Vac. Sci. Technol., A, 1998, 16, 669, DOI: 10.1116/1.581085.

18 B. Susrutha, L. Giribabu and S. P. Singh, Chem. Commun., 2015, 51, 14696, DOI: 10.1039/c5cc03666f.

19 G. Genesio, J. Maynadie, M. Carboni and D. Meyer, New J. Chem., 2018, 42, 2351, DOI: 10.1039/c7nj03171h.

20 Y. Z. Zhang, Y. Wang, T. Cheng, W. Y. Lai, H. Pang and W. Huang, Chem. Soc. Rev., 2015, 44, 5181, DOI: 10.1039/ c5cs00174a.

21 B. Yao, J. Zhang, T. Kou, Y. Song, T. Liu and Y. Li, Adv. Sci., 2017, 4, 1, DOI: 10.1002/advs.201700107.

22 Y. Lin, D. Gritsenko, Q. Liu, X. Lu and J. Xu, ACS Appl. Mater. Interfaces, 2016, 8, 20501, DOI: 10.1021/acsami.6b04854.

23 L. Yuan, B. Yao, B. Hu, K. Huo, W. Chen and J. Zhou, Energy Environ. Sci., 2013, 6, 470, DOI: 10.1039/c2ee23977a.

24 C. Z. Meng, C. H. Liu, L. Z. Chen, C. H. Hu and S. S. Fan, Nano Lett., 2010, 10, 4025, DOI: 10.1021/nl1019672.

25 Z. Weng, Y. Su, D. W. Wang, F. Li, J. Du and H. Ming Cheng, Adv. Energy Mater., 2011, 1, 917, DOI: 10.1002/ aenm.201100312.

26 R. Liu, S. Il Cho and S. B. Lee, Nanotechnology, 2008, 19, 1, DOI: 10.1088/0957-4484/19/21/215710.

27 L. li Jiang, X. Lu, C. M. Xie, G. J. Wan, H. P. Zhang and T. Youhong, J. Phys. Chem. C, 2015, 119, 3903, DOI: 10.1021/jp511022z.

28 J. Cao, Y. Wang, J. Chen, X. Li, F. C. Walsh, J. Hu Ouyang, D. Jia and Y. Zhoua, J. Mater. Chem. A, 2015, 3, 14445, DOI: 10.1039/c5ta02920a.

29 J. Tao, N. Liu, W. Ma, L. Ding, L. Li, J. Su and Y. Gao, Sci. Rep., 2013, 3, 2286, DOI: 10.1038/srep02286.

30 L. Yuan, X. Xiao, T. Ding, J. Zhong, X. Zhang, Y. Shen, B. Hu, Y. Huang, J. Zhou and Z. Lin Wang, Angew. Chem., Int. Ed., 2012, 51, 1, DOI: 10.1002/anie.201109142.
31 H. P. Cong, X. Chen Ren, P. Wang and S. H. Yu, Energy Environ. Sci., 2013, 6, 1185, DOI: .

32 A. Syafiuddin, S. M. R. Salim, A. B. H. Kueh, T. Hadibaratad and H. Nu, J. Chin. Chem. Soc., 2017, 64, 732, DOI: 10.1002/ jecs.201700067.

33 P. Sutradhar and M. Saha, J. Phys. Chem. C, 2016, 120, 8941, DOI: 10.1021/acs.jpcc.6b00075.

34 C. M. Correa, R. Faez, M. A. Bizeto and F. F. Camilo, $R S C$ $A d v .$, 2012, 2, 3088, DOI: 10.1039/c2ra00992g.

35 S. Dhibar and C. Kumar Das, Ind. Eng. Chem. Res., 2014, 53, 3495, DOI: 10.1021/ie402161e.

36 E. Pintér, R. Patakfalvi, T. Fülei, Z. Gingl, I. Dékány and C. Visy, J. Phys. Chem. B, 2005, 109, 17474, DOI: 10.1021/ jp0517652.

37 A. Singh, Z. Salmi, N. Joshi, P. Jha, A. Kumar, H. Lecoq, S. Lau, M. M. Chehimi, D. K. Aswal and S. K. Gupta, RSC Adv., 2013, 3, 5506, DOI: 10.1039/C3RA22981E.

38 I. P. Santos and L. M. L. Marzan, Adv. Funct. Mater., 2009, 19, 679, DOI: 10.1002/adfm.200801566.

39 L. He and S. Chin Tjong, RSC Adv., 2015, 5, 15070, DOI: 10.1039/c5ra00257e.

40 A. Aashish, N. K. Sadanandhan, K. P. Ganesan, U. S. Hareesh, S. Muthusamy and S. J. Devaki, ACS Omega, 2018, 3, 3489, DOI: 10.1021/acsomega.7b02055.

41 S. Poyraz, I. Cerkez, T. S. Huang, Z. Liu, L. Kang, J. Luo and X. Zhang, ACS Appl. Mater. Interfaces, 2014, 6, 20025, DOI: 10.1021/am505571m.

42 A. Choudhury, Sens. Actuators, B, 2009, 138, 318-325, DOI: 10.1016/j.snb.2009.01.019.

43 L. Tang, F. Duan and M. Chen, RSC Adv., 2016, 6, 6501265019, DOI: 10.1039/C6RA12442A.

44 N. K. Sadanandhan and S. J. Devaki, J. Appl. Polym. Sci., 2016, 133, 44351, DOI: 10.1002/app.44351.

45 C. Molji, A. Aashish, K. S. Neethu and S. J. Devaki, J. Mater. Chem. A, 2017, 5, 16636, DOI: 10.1039/c7ta05215d.

46 M. S. Nooshabadi and F. K. Taheri, RSC Adv., 2015, 5, 9660196610, DOI: 10.1039/c5ra14333k.

47 Y. Wang, Y. Song and Y. Xia, Chem. Soc. Rev., 2016, 45, 59255950, DOI: 10.1039/c5cs00580a.

48 M. D. Stoller and R. S. Ruoff, Energy Environ. Sci., 2010, 3, 1294-1301, DOI: 10.1039/c0ee00074d.

49 W. K. Chee, H. N. Lim, Z. Zainal, N. M. Huang, I. Harrison and Y. Andou, J. Phys. Chem. C, 2016, 120, 4153-4172, DOI: 10.1021/acs.jpcc.5b10187.

50 M. Liu, Y. E Miao, C. Zhang, W. W. Tjiu, Z. Yang, H. Peng and T. Liu, Nanoscale, 2013, 5, 7312-7320, DOI: 10.1039/ c3nr01442h.

51 K. Devarayan, J. Park, H. Y. Kim and B. S. Kim, Carbohydr. Polym., 2017, 163, 153, DOI: 10.1016/j.carbpol.2017.01.066.

52 L. Liu, Z. Niu, L. Zhang, W. Zhou, X. Chen and S. Xi, Adv. Mater., 2014, 26, 4855, DOI: 10.1002/adma.201401513.

53 Y. Xie, Y. Liu, Y. Zhao, Y. H. Tsang, S. P. Lau, H. Huang and Y. Chai, J. Mater. Chem. A, 2014, 2, 9142, DOI: 10.1039/ C4TA00734D.

54 D. Saptarshi and D. Chapal Kumar, Ind. Eng. Chem. Res., 2014, 53, 3495, DOI: 10.1021/ie402161e. 
55 K. Ghosh, C. Y. Yue, M. Miruzzaman Sk, R. K. Jena and S. Bi, Sustainable Energy Fuels, 2018, 2, 280, DOI: 10.1039/ c7se00433h.
56 L. Zhang, X. Yu, P. Zhu, F. Zhou, G. Li, R. Sun and C. Ping Wong, Sustainable Energy Fuels, 2018, 2, 147, DOI: 10.1039/ c7se00411g. 